\title{
Cross-Coupling Inductance Parameter Estimation for More Accurate Performance Evaluation of Wound-Field Flux Modulation Machines
}

\author{
Mkhululi Mabhula ${ }^{1}$ (D), Udochukwu B. Akuru ${ }^{2,3, * \mathbb{D}}$ and Maarten J. Kamper ${ }^{1}$ (D) \\ 1 Department of Electrical and Electronic Engineering, Stellenbosch University, Stellenbosch 7600, \\ South Africa; mabhulamkhululi@gmail.com (M.M.); kamper@sun.ac.za (M.J.K.) \\ 2 Department of Electrical Engineering, Tshwane University of Technology, Pretoria 0183, South Africa \\ 3 Department of Electrical Engineering, University of Nigeria, Nsukka, Enugu State 410001, Nigeria \\ * Correspondence: AkuruUB@tut.ac.za; Tel.: +27-12-382-5605
}

Received: 28 August 2020; Accepted: 8 October 2020; Published: 22 October 2020

\begin{abstract}
In this paper, a proposed numerical frozen permeability modeling procedure is fully derived to accurately estimate the parameters of two variants of wound-field flux modulation machines (WF-FMMs) namely: wound-field flux switching machine (WF-FSM) and DC-excited vernier reluctance machine (DC-VRM). During the procedure, the contribution of saturation to the variation of the machine parameters is investigated. The parameter variation effects on the machine performance is also investigated. It is shown that analysis of WF-FMMs is better understood by using the proposed procedure which computes accurately the machine parameters.
\end{abstract}

Keywords: cross-coupling; finite element method (FEM); flux linkages; two-axis modeling; wound-field flux modulation machines

\section{Introduction}

High torque capability per volume is the most desired performance characteristics among electrical machine designers today, of which permanent magnet (PM) machines are prioritized candidates. However, the need to design and continuously highlight alternative non-PM machine topologies has been a recent norm, given the rare-earth PM commodity price issues which surfaced between 2011 and 2012 [1].

Among the available high torque density machines are the recently emerged flux modulation (FM) machines, which operate on the so-called FM principle, i.e., the presence of a flux modulator ensures that a magnetic gearing effect is always propagated [2]. Whereby majority of FM machines are PM-based, the possibility to implement them as non-PM machines, using purely field-winding coils, is very established, although it goes without saying that the torque density could be less appealing. Notwithstanding, wound-field flux modulation machines (WF-FMMs) such as the wound-field flux switching machine (WF-FSM) and the DC-excited Vernier reluctance machine (DC-VRM) are very attractive in that they are non-PM variants with mainly stator-mounted coils, which means they are neither threatened by demagnetization nor do they need slip rings and brushes unlike in classical wound-rotor synchronous machines. Moreover, their robust rotor and concentrated winding structures are further impetus to their easy manufacturability, high reliability and wide utility [3-5].

However, one of the main challenges with WF-FMMs is in terms of high magnetic saturation which limits their overload capability. Due to deep saturation and high armature reaction effects when operating in overload mode, the inductance prediction is affected, leading to distinct self- and mutual-components during excitation of the field and/or armature windings [6-8]. Previous studies, which attempted the determination of the inductance components in PM-FSM are very basic and do 
not elucidate on the mutual (cross-coupling) components [9,10]. Similarly, one study which looked at the torque ripple analysis in DC-VRM attributed to the self- and mutual-inductances in the evaluation of the electromagnetic torque, but fell short on how to estimate them [11]. The torque separation of the hybrid-excited (HE)-FSM, as proposed using the frozen permeability method (FPM), is done only with reference to the self-inductances [12]. However, it has been shown, even for wound-rotor synchronous motors that the cross-coupling inductances can be severe under saturation, and do affect the effective torque, among others $[8,13]$. Therefore, the existence and prominence of the cross-coupling inductance in WF-FMMs, where both the field and armature windings are collocated on the same core, is expected to be much more, leading to certain defects in machine performance such as in torque and power factor calculations.

In this paper, an analytic cum numerical procedure based on the FPM is developed in the study to accurately estimate the self- and mutual-inductance parameters of the two variants of the WF-FMM i.e., WF-FSM and DC-VRM, while also evaluating the effects on machine performance, especially under deep saturation. The complete characterization of the inductance parameters in these machines helps in the accurate design, performance prediction, fault-tolerance analysis and control of these machines, while providing proper estimation on errors being incurred due to the ignorance of the cross-coupling inductances in the performance analysis of the benchmark WF-FMMs.

In the following section, the proposed FPM modeling procedure is fully derived for the desired performance variables. This is then followed up with simulated results and discussion from 2D finite element method (FEM) in Section 3, and based on some design benchmarks of the proposed machines. It is also in this section where the validation of the proposed FPM modeling using a commercial FEM software package is given. Lastly in Section 4, some conclusions are drawn.

\section{Proposed Modeling}

The steady-state FEM modeling approach which uses the decomposed total flux linkages of the machine is proposed. The flux linkages are net flux linkages produced by the currents from which parameters of the machine are determined, which guarantees accuracy of the modeling approach. Additionally, it is not only the non-linear operating region of the machine dealt with, but also the cross-magnetization and saturation saliency effects on the machine incorporating high-order harmonic and leakage fluxes produced by the winding and slotted air gap. With these decomposed total flux linkages, the inductance and performance variables of the machine can be calculated accurately.

In the case of a current-fed machine, the FEM uses the magnetic vector potential approach to solve for the Maxwell equations that describe fields in the magneto-static problem given by

$$
\begin{aligned}
\nabla \cdot \bar{B} & =0 \\
\nabla \times \bar{H} & =\bar{J},
\end{aligned}
$$

where $\bar{B}, \bar{H}$ and $\bar{J}$ are magnetic flux density, magnetic field intensity and current density vectors, respectively. The latter is done by finding the vector potential $(\bar{A})$ which satisfies

$$
\nabla \times(v \nabla \times \bar{A})=\bar{J},
$$

where $v$ is the reluctivity of the material. In 2D problem applications, $\bar{A}$ and $\bar{J}$ of (3) only have the $\mathrm{z}$ component. The total current flowing through a coil of surface area $(s)$ is calculated from

$$
I=\int_{\mathrm{s}} \bar{J} d s
$$


Utilizing Park's transformation [14] i.e., direct (d) and quadrature (q) axes rotating at electrical angular frequency $\left(\omega_{\mathrm{e}}\right)$ fixed on the rotor, for a given electrical rotor position $\left(\theta_{\mathrm{e}}\right)$, the current source (or stator) $\mathrm{k}^{\text {th }}$ phase is calculated as

$$
i_{\mathrm{k}}=I_{\mathrm{d}} \cos \left[\theta_{\mathrm{e}}-(\mathrm{k}-1) \frac{2 \pi}{m}\right]-I_{\mathrm{q}} \sin \left[\theta_{\mathrm{e}}-(\mathrm{k}-1) \frac{2 \pi}{m}\right], \mathrm{k}=1,2, \ldots, m .
$$

where $m$ is the number of phases. The magnetic fields are then obtain, followed by the $\mathrm{k}^{\text {th }}$ phase flux linkages calculated as

$$
\lambda_{\mathrm{k}}=\ell \sum_{\mathrm{j}} N_{\mathrm{kj}} \frac{1}{S_{\mathrm{j}}} \int_{S_{\mathrm{j}}} \bar{A} d S,
$$

where $\ell$ is the machine length, $S_{\mathrm{j}}$ is the surface area of the $\mathrm{j}^{\text {th }}$ slot and $N_{\mathrm{kj}}$ is the number of conductors in the $\mathrm{j}^{\text {th }}$ of the $\mathrm{k}^{\text {th }}$ phase. Additionally, utilizing Park' transformation, the stator $\mathrm{d}\left(\Lambda_{\mathrm{d}}\right)$ and $\mathrm{q}\left(\Lambda_{\mathrm{q}}\right)$ axes total flux linkage components are calculated as

$$
\begin{aligned}
& \Lambda_{\mathrm{d}}=\frac{2}{m} \sum_{k=1}^{m} \lambda_{\mathrm{k}} \cos \left[\theta_{\mathrm{e}}-(\mathrm{k}-1) \frac{2 \pi}{m}\right] \\
& \Lambda_{\mathrm{q}}=-\frac{2}{m} \sum_{k=1}^{m} \lambda_{\mathrm{k}} \sin \left[\theta_{\mathrm{e}}-(\mathrm{k}-1) \frac{2 \pi}{m}\right] .
\end{aligned}
$$

Taking $m=3$, the stator phases (i.e., 1, 2 and 3) and dq-axes relative positions of the current and flux linkage components are defined in Figure 1 where $\alpha$ and $\beta$ are current and flux linkage angles respectively. Thus, both current and flux linkage dq-axes components can be expressed in terms of their respective magnitudes $(I$ and $\Lambda)$ and angles as

$$
\begin{aligned}
I_{\mathrm{d}} & =I \cos (\alpha), \quad I_{\mathrm{q}}=I \sin (\alpha) \\
\Lambda_{\mathrm{d}} & =\Lambda \cos (\beta), \quad \Lambda_{\mathrm{q}}=\Lambda \sin (\beta) .
\end{aligned}
$$

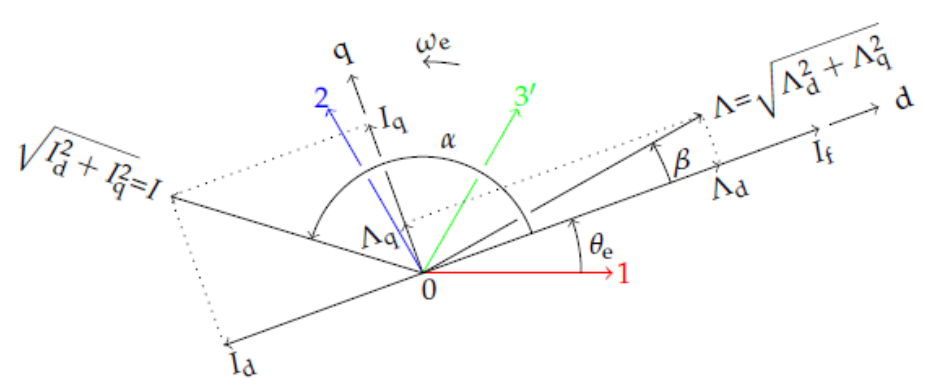

Figure 1. Wound-field flux modulation machine (WF-FMM) phasor diagram as generator showing 123-phases and dq-axes relative positions.

In general, $\Lambda_{\mathrm{d}}$ and $\Lambda_{\mathrm{q}}$ of (7) depend on $I_{\mathrm{d}}, I_{\mathrm{q}}, I_{\mathrm{f}}$ (field current) and $\theta_{\mathrm{e}}$ such that

$$
\begin{aligned}
& \Lambda_{\mathrm{d}}=\Lambda_{\mathrm{d}}\left(I_{\mathrm{d}}, I_{\mathrm{q}}\right) \\
& \Lambda_{\mathrm{q}}=\Lambda_{\mathrm{q}}\left(I_{\mathrm{q}}, I_{\mathrm{q}}\right) .
\end{aligned}
$$

It is important to state that $I_{\mathrm{f}}$ (field current) and $\theta_{\mathrm{e}}$ are not given as variables of (9) as the study in this paper is to show only the effect of the dq-axes currents (8) on the inductances and performance of the machines. 
In the case of the classical (conventional) synchronous machines with sine-distributed windings and no saturation, $\Lambda_{\mathrm{d}}$ and $\Lambda_{\mathrm{q}}$ can be represented by simple dq-axes inductance terms, from Figure 1 in generator mode as [15]

$$
\begin{aligned}
& \Lambda_{\mathrm{d}}=-L_{\mathrm{dd}}^{\mathrm{eq}} I \cos (\alpha)+L_{\mathrm{df}}^{\mathrm{eq}} I_{\mathrm{f}} \\
& \Lambda_{\mathrm{q}}=-L_{\mathrm{qq}}^{\mathrm{eq}} I \sin (\alpha),
\end{aligned}
$$

where the equivalent dq-axes inductances $\left(L_{\mathrm{dd}}^{\mathrm{eq}}, L_{\mathrm{qq}}^{\mathrm{eq}}\right.$ and $\left.L_{\mathrm{df}}^{\mathrm{eq}}\right)$ are given by conventional calculated self-inductances $\left(L_{\mathrm{dd}}^{\mathrm{co}}, L_{\mathrm{qq}}^{\mathrm{co}}\right.$ and $\left.L_{\mathrm{df}}^{\mathrm{co}}\right)$ as

$$
\begin{aligned}
L_{\mathrm{dd}}^{\mathrm{eq}} & =L_{\mathrm{dd}}^{\mathrm{co}} \\
L_{\mathrm{qq}}^{\mathrm{eq}} & =L_{\mathrm{qq}}^{\mathrm{co}} \\
L_{\mathrm{df}}^{\mathrm{eq}} & =L_{\mathrm{df}}^{\text {co }} .
\end{aligned}
$$

As stated in the introduction, due to deep saturation and high armature reaction effects when operating WF-FMMs in overload mode, the inductance prediction is affected, leading to distinct self- and mutual-components during double excitation. Hence, the model of (10) is not complete. For a complete model, all the effects of saturation must be included, thus according to the complete model in [13,16], Equation (11) is replaced by a simplified expression given as

$$
\begin{aligned}
& L_{\mathrm{dd}}^{\mathrm{eq}}=L_{\mathrm{dd}}^{\mathrm{ac}}+L_{\mathrm{dq}}^{\mathrm{ac}} \frac{I_{\mathrm{q}}}{I_{\mathrm{d}}}=L_{\mathrm{dd}}^{\mathrm{ac}}+\left\{L_{\mathrm{dq}}^{\mathrm{ac}} I \tan (\alpha)\right\} \\
& L_{\mathrm{qq}}^{\mathrm{eq}}=L_{\mathrm{qq}}^{\mathrm{ac}}+\frac{L_{\mathrm{qd}}^{\mathrm{ac}} I_{\mathrm{d}}+L_{\mathrm{qf}}^{\mathrm{ac}} I_{\mathrm{f}}}{I_{\mathrm{q}}}=L_{\mathrm{qq}}^{\mathrm{ac}}+\left\{L_{\mathrm{qd}}^{\mathrm{ac}} I \cot (\alpha)+L_{\mathrm{qf}}^{\mathrm{ac}} \frac{I_{\mathrm{f}}}{I_{\mathrm{q}}}\right\} \\
& L_{\mathrm{df}}^{\mathrm{eq}}=L_{\mathrm{df}}^{\mathrm{ac}} .
\end{aligned}
$$

In Equation (12), the non-classical (actual) calculated inductances $L_{\mathrm{dd}}^{\mathrm{ac}}$ and $L_{\mathrm{qq}}^{\mathrm{ac}}$ are due to $I_{\mathrm{d}}$ and $I_{\mathrm{q}}$, respectively, $L_{\mathrm{df}}^{\text {ac }}$ are due to $I_{\mathrm{f}}$ and $L_{\mathrm{dq}}^{\text {ac }}, L_{\mathrm{qd}}^{\text {ac }}$ and $L_{\mathrm{qf}}^{\mathrm{ac}}$ are due to axes cross-coupling. Note, the error in inductances of (12) are given by the terms in curl brackets. Only the accuracy to which these parameters are predicted will influence the accuracy of the rotor position estimation $[17,18]$. In addition, to solve for currents, given voltages are only accurate if the terms in curl brackets of (12) are included. Thus, the calculation methodology of WF-FMM inductances is extremely critical. The latter is implemented using classical and non-classical numerical analysis methods.

In both classical and non-classical numerical methods of calculating inductances, any operating point is defined by exciting the machine with all currents $\left(I_{\mathrm{d}}, I_{\mathrm{q}}\right.$ and $\left.I_{\mathrm{f}}\right)$. A non-linear magneto-static simulation is then performed. The latter is to obtain the total dq-axis flux linkages $\left(\Lambda_{d}\right.$ and $\left.\Lambda_{q}\right)$ of $(10)$. Thus, a non-linear solution is conducted with all $I_{\mathrm{d}}, I_{\mathrm{q}}$ and $I_{\mathrm{f}}$, resulting in all $m$-phase currents given by (5). The corresponding all $m$-phase total flux linkages of (6) are then calculated using the obtained solution for magnetic vector potential according to (3), and dq-axes total flux linkages of (10) are then calculated as

$$
\begin{aligned}
& \Lambda_{\mathrm{d}}=\frac{2}{m} \sum_{k=1}^{m} \lambda_{\mathrm{k}} \cos \left[\theta_{\mathrm{e}}-(\mathrm{k}-1) \frac{2 \pi}{m}\right] \\
& \Lambda_{\mathrm{q}}=-\frac{2}{m} \sum_{k=1}^{m} \lambda_{\mathrm{k}} \sin \left[\theta_{\mathrm{e}}-(\mathrm{k}-1) \frac{2 \pi}{m}\right]^{\prime} \quad\left(I_{\mathrm{d}}, I_{\mathrm{q}}, I_{\mathrm{f}}\right) .
\end{aligned}
$$

To determine the conventional calculated inductances of (11) at an operating point defined in (13), a single non-linear magneto-static simulation is performed. The non-linear solution is conducted by setting $I_{\mathrm{d}}$ and $I_{\mathrm{q}}$ to zero and having only $I_{\mathrm{f}}$, to calculate the d-axis flux linkage $\left(\Lambda_{\mathrm{d}}^{\text {co }}\right)$ due to $I_{\mathrm{f}}$ current 
excitation i.e., $L_{\mathrm{df}}^{\mathrm{eq}} I_{\mathrm{f}}$ in (10). All $m$-phase field flux linkages of (6) are then calculated using the obtained solution for magnetic vector potential according to (3), and the d-axis conventional flux linkage is then calculated as

$$
\Lambda_{\mathrm{d}}^{\mathrm{co}}=\frac{2}{m} \sum_{k=1}^{m} \lambda_{\mathrm{k}} \cos \left[\theta_{\mathrm{e}}-(\mathrm{k}-1) \frac{2 \pi}{m}\right], \quad\left(I_{\mathrm{d}}=I_{\mathrm{q}}=0, I_{\mathrm{f}}\right)
$$

In Equation (14), the q-axis conventional calculated flux linkage $\Lambda_{\mathrm{q} 2}^{\text {co }}=0$ since classically, the field winding is assumed to be aligned with the $\mathrm{d}$-axis and only generates $\mathrm{d}$-axis flux. The conventional calculated inductances in (12) are then determined from (13) and (14) as

$$
\begin{aligned}
& L_{\mathrm{dd}}^{\mathrm{co}}=\left(\Lambda_{\mathrm{d}}-\Lambda_{\mathrm{d}}^{\mathrm{co}}\right) / I_{\mathrm{d}} \\
& L_{\mathrm{qq}}^{\mathrm{co}}=\Lambda_{\mathrm{q}} / I_{\mathrm{q}} \\
& L_{\mathrm{df}}^{\mathrm{co}}=\Lambda_{\mathrm{d}}^{\mathrm{co}} / I_{\mathrm{f}} .
\end{aligned}
$$

The most optimal strategy to determine the actual inductances of (12) at any operating point as defined in (13) and still preserve all the information about saturation in the machine is by utilizing the proposed FPM [13]. Using the FPM, the total flux linkages can be decomposed into components due to individual current excitations (i.e., $I_{\mathrm{d}}$ or $I_{\mathrm{q}}$ and or $I_{\mathrm{f}}$ ). Thus at a certain operating point set by all $I_{\mathrm{d}}, I_{\mathrm{q}}$ and $I_{\mathrm{f}}$ currents (i.e., (13)), a non-linear magneto-static simulation is performed in order to obtain the values of the permeabilities in the nodes of the FE mesh. The values of the obtained (i.e., frozen) permeabilities are then used to conduct three linear magneto-static simulations $(i=1,2$ and 3) to obtain dq-axes flux linkages $\left(\Lambda_{\mathrm{di}}^{\mathrm{ac}}\right.$ and $\left.\Lambda_{\mathrm{qi}}^{\mathrm{ac}}\right)$ from which $L_{\mathrm{dd}}^{\mathrm{ac}}, L_{\mathrm{qq}}^{\mathrm{ac}}, L_{\mathrm{dq}}^{\mathrm{ac}}, L_{\mathrm{qd}}^{\mathrm{ac}}, L_{\mathrm{df}}^{\mathrm{ac}}$ and $L_{\mathrm{qf}}^{\mathrm{ac}}$ of $(12)$ are determined. By freezing the permeabilities all inductances (i.e., self and mutual) can be computed with high precision [19].

The first linear simulation ( $\mathrm{i}=1)$ is conducted by setting $I_{\mathrm{d}}$ and $I_{\mathrm{q}}$ to zero and having only $I_{\mathrm{f}}$. All $m$-phase flux linkages of (6) are then calculated using the obtained solution for magnetic vector potential according to (3), and dq-axes actual flux linkages are then calculated as

$$
\begin{aligned}
& \Lambda_{\mathrm{d} 1}^{\mathrm{ac}}=\frac{2}{m} \sum_{k=1}^{m} \lambda_{\mathrm{k}} \cos \left[\theta_{\mathrm{e}}-(\mathrm{k}-1) \frac{2 \pi}{m}\right] \\
& \Lambda_{\mathrm{q} 1}^{\mathrm{ac}}=-\frac{2}{m} \sum_{k=1}^{m} \lambda_{\mathrm{k}} \sin \left[\theta_{\mathrm{e}}-(\mathrm{k}-1) \frac{2 \pi}{m}\right],\left(\mathrm{i}=1: I_{\mathrm{d}}=I_{\mathrm{q}}=0, I_{\mathrm{f}}\right) .
\end{aligned}
$$

The saturated values $f$-axis and the cross-axes inductances $L_{\mathrm{df}}^{\mathrm{ac}}$ and $L_{\mathrm{qf}}^{\mathrm{ac}}$ in (12) are respectively determined from

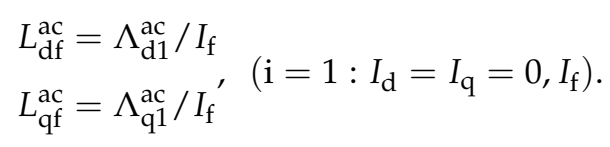

The second linear simulation ( $\mathrm{i}=2)$ is conducted with only $I_{\mathrm{d}}$, while $I_{\mathrm{f}}$ and $I_{\mathrm{q}}$ are set to zero, resulting in all $m$-phase currents of (5) given by

$$
i_{\mathrm{k}}=I_{\mathrm{d}} \cos \left[\theta_{\mathrm{e}}-(\mathrm{k}-1) \frac{2 \pi}{m}\right], \quad(k=1,2, \ldots, m) .
$$

The corresponding all $m$-phase flux linkages are calculated using the obtained solution for magnetic vector potential, according to (3), and the actual flux linkages $\Lambda_{\mathrm{d} 2}^{\mathrm{ac}}$ and $\Lambda_{\mathrm{q} 2}^{\mathrm{ac}}$ are calculated 
as in (16). The saturated d-axis and cross-axes inductances $L_{\mathrm{dd}}^{\mathrm{ac}}$ and $L_{\mathrm{qd}}^{\mathrm{ac}}$ in (12) are respectively determined from

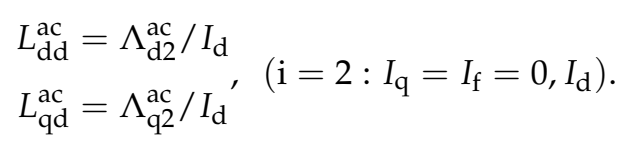

The third linear simulation ( $\mathrm{i}=3$ ) is conducted with only $I_{\mathrm{q}}$, while $I_{\mathrm{f}}$ and $I_{\mathrm{d}}$ are set to zero, resulting in all $m$-phase currents of (5) given by

$$
i_{\mathrm{k}}=-I_{\mathrm{q}} \sin \left[\theta_{\mathrm{e}}-(\mathrm{k}-1) \frac{2 \pi}{m}\right], \quad(k=1,2, \ldots, m) .
$$

The corresponding all $m$-phase flux linkages are calculated using the obtained solution for magnetic vector potential, according to (3), and the actual flux linkages $\Lambda_{\mathrm{d} 3}^{\mathrm{ac}}$ and $\Lambda_{\mathrm{q} 3}^{\mathrm{ac}}$ are calculated as in (16). The saturated d-axis and cross-axes inductances $L_{\mathrm{qq}}^{\mathrm{ac}}$ and $L_{\mathrm{dq}}^{\mathrm{ac}}$ are calculated as

$$
\begin{aligned}
& L_{\mathrm{dq}}^{\mathrm{ac}}=\Lambda_{\mathrm{d} 3}^{\mathrm{ac}} / I_{\mathrm{q}} \\
& L_{\mathrm{qq}}^{\mathrm{ac}}=\Lambda_{\mathrm{q} 3}^{\mathrm{ac}} / I_{\mathrm{q}}, \quad\left(\mathrm{i}=3: I_{\mathrm{d}}=I_{\mathrm{f}}=0, I_{\mathrm{q}}\right) .
\end{aligned}
$$

It should be noted that the dq-axes non-linear magneto-static solution of (13) is equal to the sum of the three respective individual linear magneto-static solution discussed in (16)-(21) i.e.,

$$
\Lambda_{\mathrm{d}}, \Lambda_{\mathrm{q}}=\sum_{\mathrm{i}=1}^{3} \Lambda_{\mathrm{di}}^{\mathrm{ac}}, \Lambda_{\mathrm{qi}}^{\mathrm{ac}}
$$

For the WF-FMM performance, the variables discussed in this paper are defined as the saliency $\left(k_{\mathrm{s}}\right)$, and field $\left(k_{\mathrm{f}}\right)$ ratios, the electromagnetic torque $\left(T_{\mathrm{e}}\right)$ and the power factor $(\mathrm{PF})$. The actual calculated inductances of (17), (19) and (21) determined from the FPM are used in the calculation to give a better representation of the performance variables.

The saliency and field ratios are calculated as

$$
\begin{aligned}
& k_{\mathrm{s}}=\left|L_{\mathrm{qq}}^{\mathrm{ac}} / L_{\mathrm{dd}}^{\mathrm{ac}}\right| \\
& k_{\mathrm{f}}=\left|L_{\mathrm{qf}}^{\mathrm{ac}} / L_{\mathrm{df}}^{\mathrm{ac}}\right| .
\end{aligned}
$$

The electromagnetic torque, generated by the interaction between the total current and flux linkage components is calculated by

$$
T_{\mathrm{e}}=1.5 Q\left[-\Lambda_{\mathrm{q}} I_{\mathrm{d}}+\Lambda_{\mathrm{d}} I_{\mathrm{q}}\right]
$$

where $Q$ is the rotor teeth number of the WF-FMM. Furthermore, to understand the effect of inductances on the torque, the torque of (24), redefined as

$$
T_{\mathrm{e}}=T_{\mathrm{f}}+T_{\mathrm{r}}+T_{\mathrm{m}}
$$

is calculated using inductances where

$$
\begin{gathered}
T_{\mathrm{f}}=1.5 Q I_{\mathrm{f}}\left(L_{\mathrm{df}}^{\mathrm{ac}} I_{\mathrm{q}}-L_{\mathrm{qf}}^{\mathrm{ac}} I_{\mathrm{d}}\right) \\
T_{\mathrm{r}}=1.5 Q\left(L_{\mathrm{dd}}^{\mathrm{ac}}-L_{\mathrm{qq}}^{\mathrm{ac}}\right) I_{\mathrm{d}} I_{\mathrm{q}} \\
T_{\mathrm{m}}=1.5 Q\left(L_{\mathrm{dq}}^{\mathrm{ac}} I_{\mathrm{q}}^{2}-L_{\mathrm{qd}}^{\mathrm{ac}} I_{\mathrm{d}}^{2}\right)
\end{gathered}
$$

In Equation (25), $T_{\mathrm{f}}, T_{\mathrm{r}}$ and $T_{\mathrm{m}}$ are the field, reluctance (saliency) and mutual torques, respectively. 
In addition, knowing the stator phase resistance $\left(R_{\mathrm{s}}\right)$, the power factor is calculated from the scalar product of current and terminal voltage components, as

$$
\mathrm{PF}=\left(V_{\mathrm{d}} I_{\mathrm{d}}+V_{\mathrm{q}} I_{\mathrm{q}}\right) / V I,
$$

where $I$ is given in Figure 1,

$$
\begin{aligned}
& V_{\mathrm{d}}=-R_{\mathrm{s}} I_{\mathrm{d}}+\omega_{\mathrm{e}} L_{\mathrm{qq}}^{\mathrm{eq}} \\
& V_{\mathrm{q}}=-R_{\mathrm{s}} I_{\mathrm{q}}-\omega_{\mathrm{e}} L_{\mathrm{dd}}^{\mathrm{eq}}+\omega_{\mathrm{e}} L_{\mathrm{df}}^{\mathrm{eq}} I_{\mathrm{f}},
\end{aligned}
$$

and $V=\sqrt{V_{\mathrm{d}}^{2}+V_{\mathrm{q}}^{2}}$. The equivalent inductances in (28) are of (12). In addition, to understand the effect of the different inductances on the power factor, if $R_{\mathrm{S}}$ is ignored in (28), then the power factor of (27) is expressed by

$$
\mathrm{PF}=\frac{-\Lambda_{\mathrm{q}} I_{\mathrm{d}}+\Lambda_{\mathrm{d}} I_{\mathrm{q}}}{I \Lambda}=\frac{\left[\left(L_{\mathrm{qq}}^{\mathrm{eq}}-L_{\mathrm{dd}}^{\mathrm{eq}}\right) I \sin (\alpha)+L_{\mathrm{df}}^{\mathrm{eq}} I_{\mathrm{f}}\right] \sin (\alpha)}{\Lambda},\left(R_{\mathrm{s}}=0\right) .
$$

In Equation (29), $\Lambda$ given in Figure 1 is the magnitude of the dq-axes total flux linkages.

\section{Simulation Results}

An in-house static FEM software package which uses total flux linkages on the machine solution domain is utilized in the simulation results of both WF-FMMs [20]. These total flux linkages are the net flux linkages which include high-order harmonics and leakage fluxes produced by the winding, slotted air gap and magnetic saturation. The latter is essential because a complete parameter prediction model of the machine is obtained.

Figure 2 shows optimized $15 \mathrm{~kW}$ WF-FMMs static 2D FEM developed models. The model meshes are carried out as user-controlled mesh. The flexible triangle nodes are used to create complex geometry triangular meshes in the solution domains.

Table 1 gives the specification of the two WF-FMMs shown in Figure 2 used in the simulations described in Section 2. A M400-50A lamination steel BH curve is used. For the current-controlled machines at rated current magnitude, the different operating points are achieved by varying the current angle $\alpha$, defined in Figure 1 and expressed in (8).
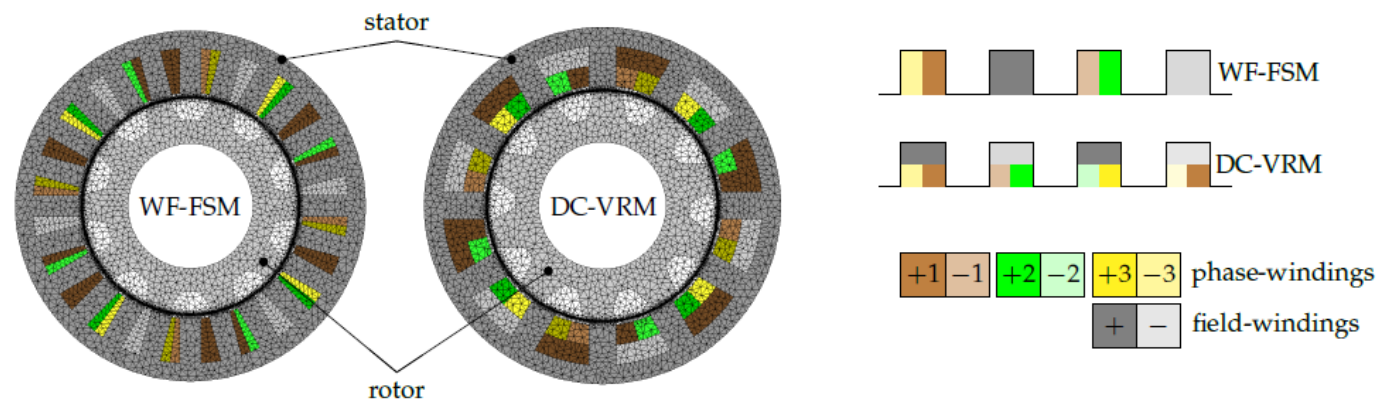

Figure 2. Three-phase WF-FMM (left) models in static 2D-FEM; Phase/DC slots: (left) 24/24 wound-field flux switching machine (WF-FSM), 12/24 DC-excited vernier reluctance machine (DC-VRM) and (right) winding configuration. 
Table 1. Major design parameters of WF-FMMs.

\begin{tabular}{cccccccc}
\hline Parameter & WF-FSM & DC-VRM & Unit & Parameter & WF-FSM & DC-VRM & Unit \\
\hline stator outer diameter & 700.0 & 700.0 & $\mathrm{~mm}$ & stator yoke height & 35.0 & 36.6 & $\mathrm{~mm}$ \\
stator inner diameter & 434.8 & 454.5 & $\mathrm{~mm}$ & rotor yoke height & 45.5 & 45.6 & $\mathrm{~mm}$ \\
shaft diameter & 250.0 & 250.0 & $\mathrm{~mm}$ & air-gap thickness & 0.8 & 0.8 & $\mathrm{~mm}$ \\
stack length & 238.3 & 126.5 & $\mathrm{~mm}$ & rotor teeth taper & 0.68 & 0.65 & $\%$ \\
rotor pole width & 68.7 & 80.1 & $\mathrm{~mm}$ & electrical speed & 209.4 & 209.4 & rads $^{-1}$ \\
slot opening width & 14.4 & 65.6 & $\mathrm{~mm}$ & lamination material & & M400-50 A & \\
\hline
\end{tabular}

Figure 3 shows the field solution using the non-linear simulation on both WF-FSM and DC-VRM machines at an operating current angle of $\alpha=90^{\circ}$, which is at or close to maximum torque. The field solution $\mathbf{P}$ in Figure 3 is a non-linear FEM solution with all currents excited, i.e., $I_{\mathrm{d}}, I_{\mathrm{q}}$ and $I_{\mathrm{f}}$.

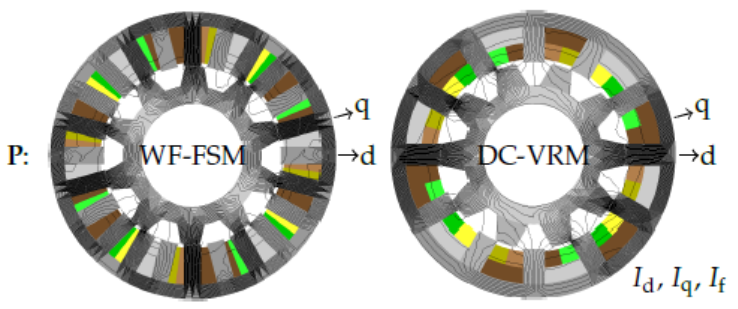

Figure 3. FEM field line solutions at rated current, current angle $\alpha=90^{\circ}$ and given rotor position for $\mathbf{P}$ : all currents non-linear FEM solution.

Figure 4 shows the field solutions using the conventional numerical method and the FPM on both the WF-FSM and DC-VRM machines at an operating defined in Figure 3. For the conventional method $\mathbf{P}$ in Figure 3 is followed by a non-linear FEM solution with field excitation, i.e., P0 of Figure 4a with only $I_{\mathrm{f}}$ current. For the FPM, freezing the element permeabilities of $\mathbf{P}$ in the Figure 3 solution is followed by three corresponding linear FEM solutions with single excitations, i.e., P1 of Figure $4 \mathrm{~b}$ with only $I_{\mathrm{f}}$ current, $\mathbf{P} 2$ of Figure $4 \mathrm{c}$ with only $I_{\mathrm{d}}$ current, and P3 of Figure $4 \mathrm{~d}$ with only $I_{\mathrm{q}}$ current.

P0:

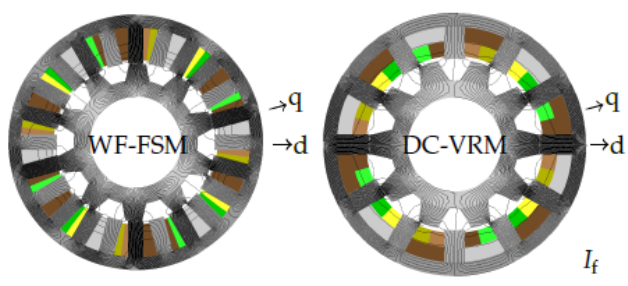

(a)

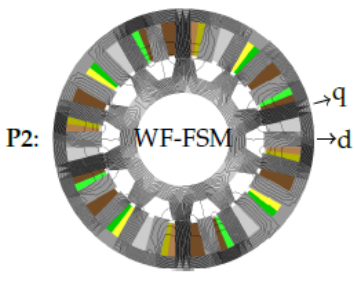

(c)

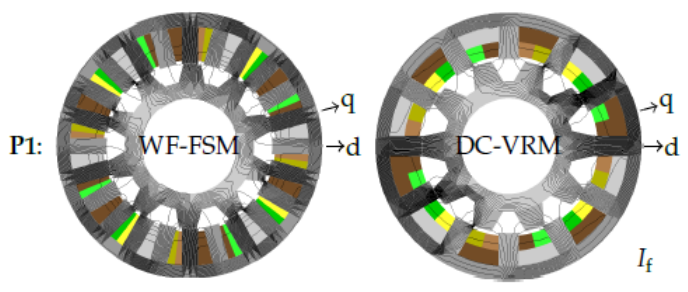

(b)
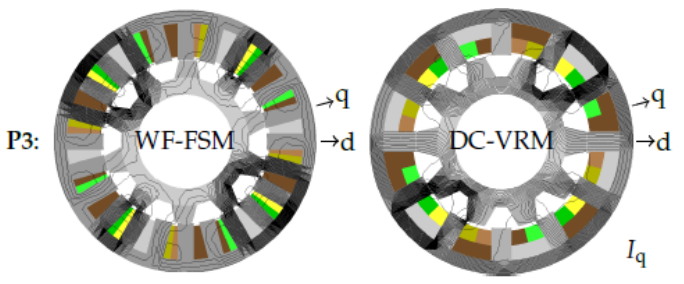

(d)

Figure 4. FEM field line solutions at rated current, current angle $\alpha=90^{\circ}$ and given rotor position for (a) P0: only $I_{\mathrm{f}}$ current non-linear FEM solution, (b) P1: only $I_{\mathrm{f}}$ current linear FEM solution, (c) P2: only $I_{\mathrm{d}}$ current linear FEM solution and (d) P3: only $I_{\mathrm{q}}$ current linear FEM solution.

The non-linear field solution $\mathbf{P}$ is used in the calculation of the total flux linkages $\left[\Lambda_{d}, \Lambda_{q}\right]$ of (13). The corresponding non-linear P0 and linear P1, P2 and P3 field solutions are used in the calculation 
of the flux linkages $\left[\Lambda_{\mathrm{d}}^{\mathrm{co}}\right]$ of (14) and $\left[\Lambda_{\mathrm{d} 1}^{\mathrm{ac}}, \Lambda_{\mathrm{q} 1}^{\mathrm{ac}}\right],\left[\Lambda_{\mathrm{d} 2}^{\mathrm{ac}}, \Lambda_{\mathrm{q} 2}^{\mathrm{ac}}\right]$ and $\left[\Lambda_{\mathrm{d} 3}^{\mathrm{ac}}, \Lambda_{\mathrm{q} 3}^{\mathrm{ac}}\right]$ as of (16), respectively. These resulting flux linkages are then used for the calculation of inductances $\left[L_{\mathrm{dd}}^{\mathrm{co}}, L_{\mathrm{qq}}^{\mathrm{co}}, L_{\mathrm{df}}^{\mathrm{co}}\right]$ according to (15) and $\left[L_{\mathrm{df}}^{\mathrm{ac}}, L_{\mathrm{qf}}^{\mathrm{ac}}\right],\left[L_{\mathrm{dd}}^{\mathrm{ac}}, L_{\mathrm{qd}}^{\mathrm{ac}}\right]$ and $\left[L_{\mathrm{dq}}^{\mathrm{ac}}, L_{\mathrm{qq}}^{\mathrm{ac}}\right]$ according to (17), (19) and (21), respectively.

It is important to state that (22) is used to check if the FPM procedure using the FEM works correctly. The correct working can also be observed in Figures 3 and 4. At solution P of Figure 3, the field line distribution is clearly dense in both excited axes. The single excited field solutions PO-P3 of Figure $4 a-d$ show less dense field line distributions and are aligned to the excited axes.

Figures 5-10 show the simulated average parameter results at different operating points i.e., $0^{\circ}<\alpha<180^{\circ}$ solved at each rotor position using the analysis described in Section 2 by calculating the mean value of all rotor position. In Figure $6, T_{\mathrm{i}}$ is the average magnetic stress tensor torque, which is shown to be the same value to the inductance calculated torque of (25). In addition, during the simulations it was found that always $L_{\mathrm{dq}}=L_{\mathrm{qd}}$; hence, in Figure 5 the inductance $L=L_{\mathrm{dq}}=L_{\mathrm{qd}}$.
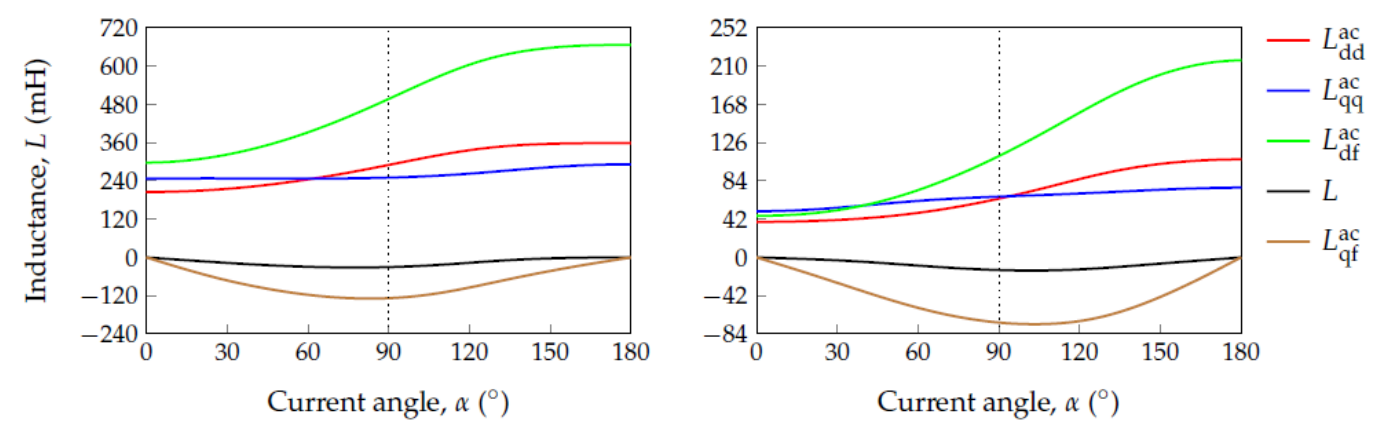

Figure 5. WF-FMM actual inductance characteristics of (left) WF-FSM and (right) DC-VRM at rated currents (phase and field) and different operating points defined by the current angle.
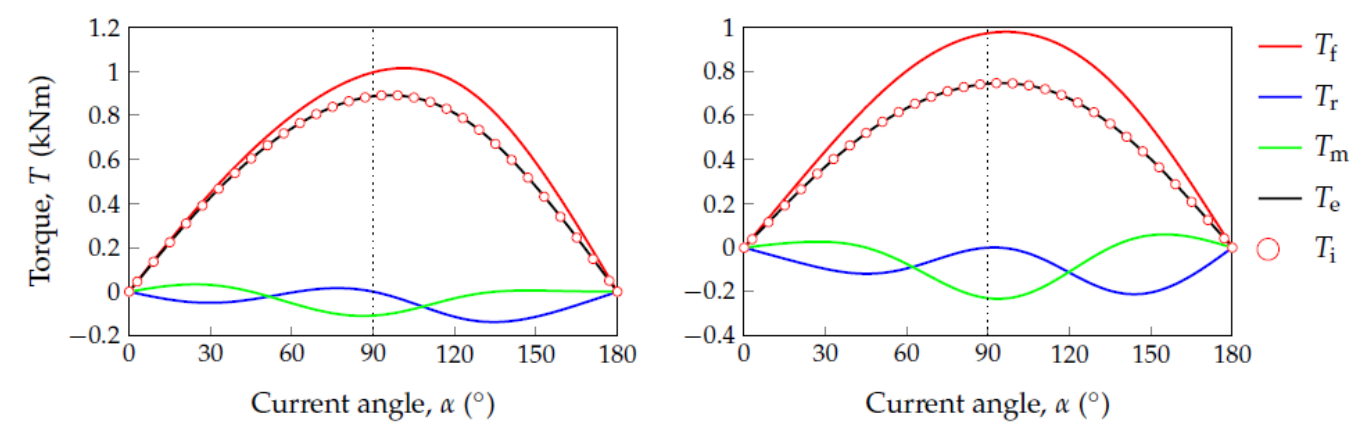

Figure 6. WF-FMM torque characteristics of (left) WF-FSM and (right) DC-VRM at rated currents (phase and field) and different operating points defined by the current angle.
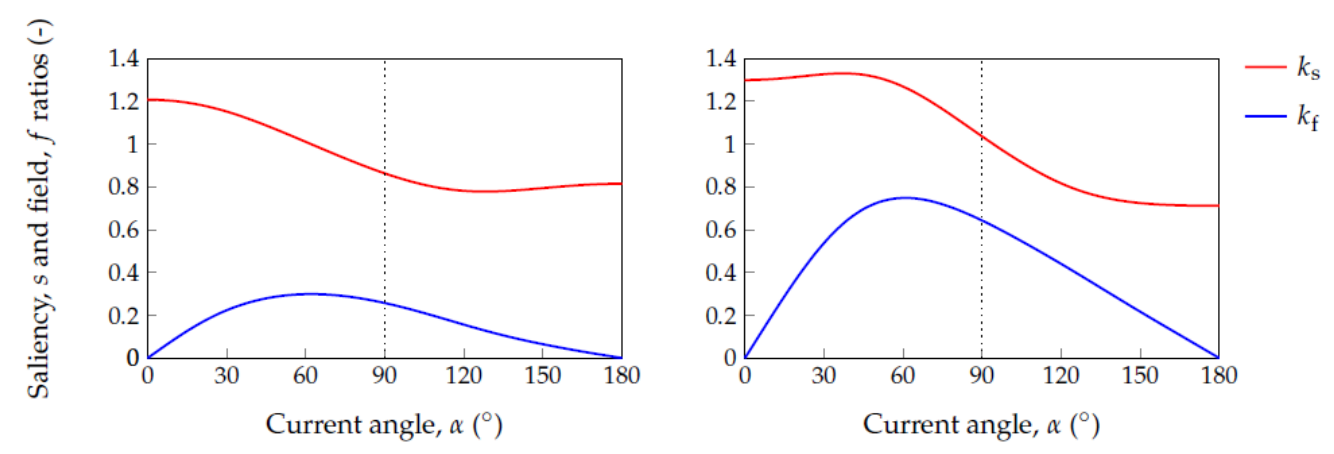

Figure 7. WF-FMM absolute saliency and field ratios characteristics of (left) WF-FSM and (right) DC-VRM at rated currents (phase and field) and different operating points defined by the current angle. 

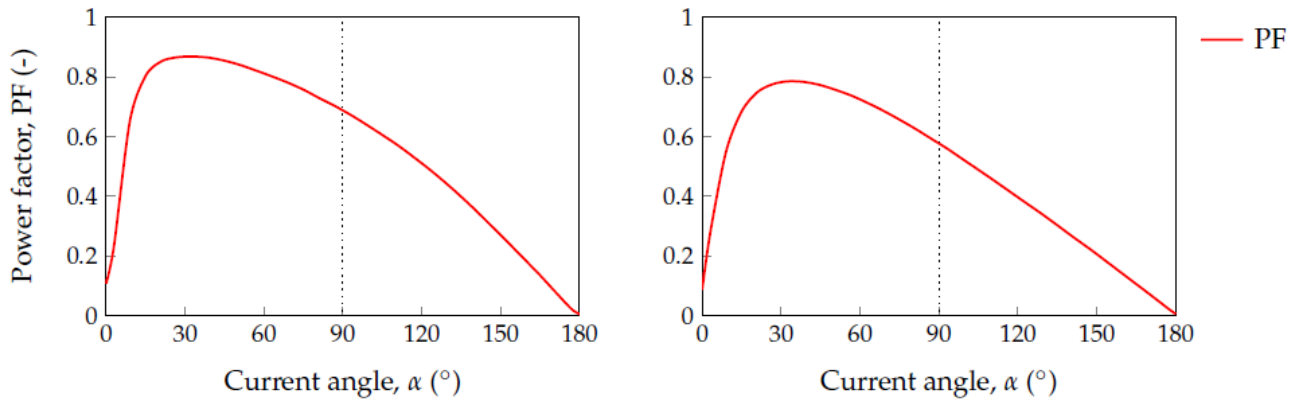

Figure 8. WF-FMM power factor characteristics of (left) WF-FSM and (right) DC-VRM at rated currents (phase and field) and different operating points defined by the current angle.
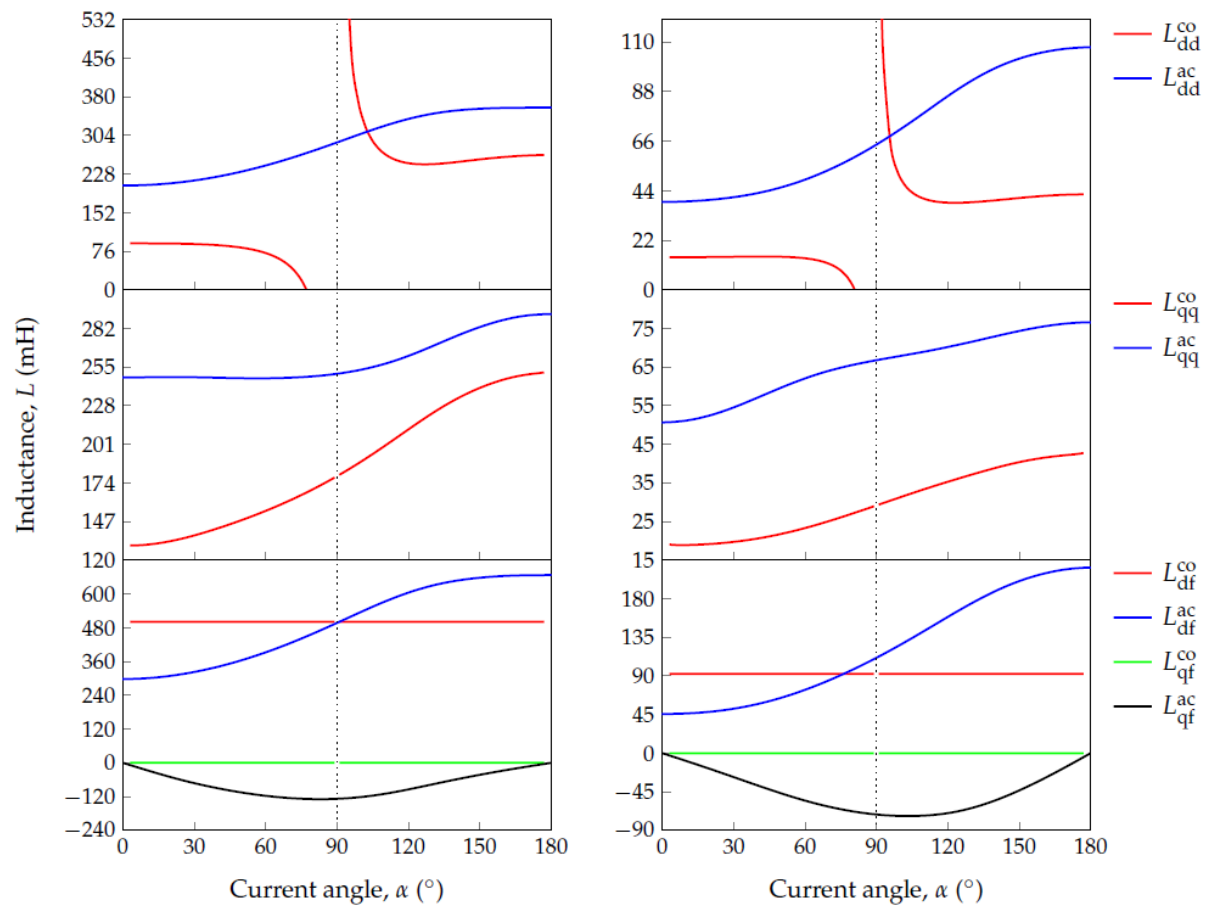

Figure 9. WF-FMM conventional and actual inductance characteristics of (left) WF-FSM and (right) DC-VRM at rated currents (phase and field) and different operating points defined by the current angle.
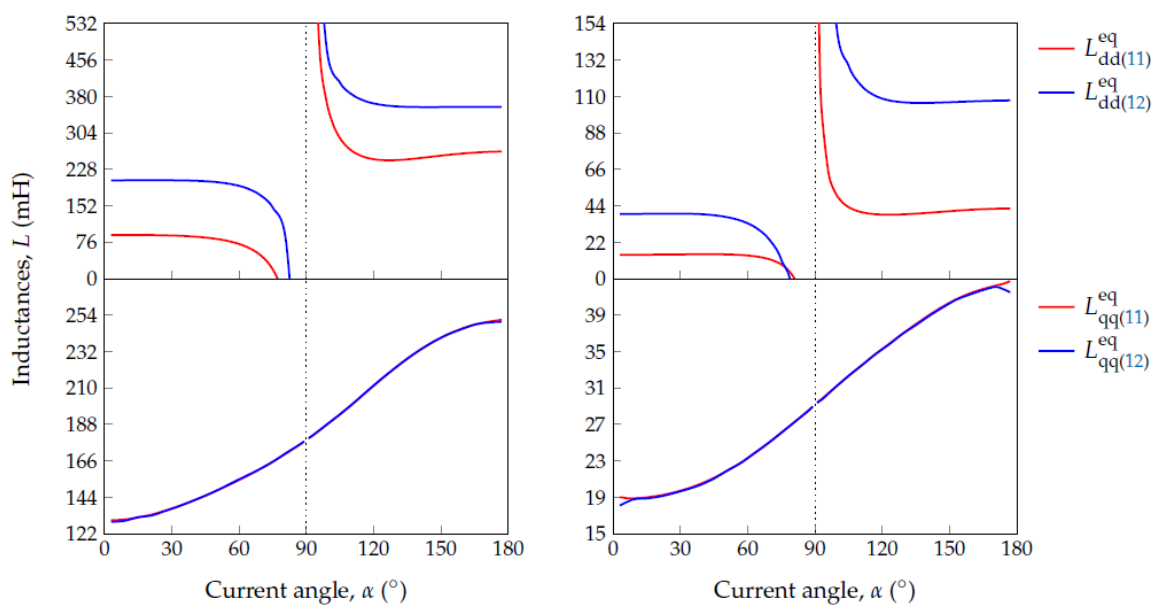

Figure 10. WF-FMM equivalent inductance characteristics of (left) WF-FSM and (right) DC-VRM at rated currents (phase and field) and different operating points defined by the current angle. 
The actual calculated inductances of (17), (19) and (21) are shown in Figure 5. It is evident that saturation has a significant effect on the dq magnetic axes of both WF-FSM and DC-VRM machines. As $\alpha$ increases, the $d$-axis comes out of saturation, especially for the DC-VRM. Accordingly, $L_{\mathrm{dd}}^{\mathrm{ac}}$ and $L_{\mathrm{df}}^{\mathrm{ac}}$ increase as shown in Figure 5. At lower values of $\alpha$, the $\mathrm{d}$-axis inductance is not considerably affected by cross-coupling i.e., $L \approx 0$. As $I_{\mathrm{q}}$ increases, cross-coupling becomes more prominent. Thus, with evidence from the d-axis inductances shown in Figure 5, the d-axis inductance is affected by the component of current on the orthogonal axis. The above described d-axis analysis can also be applied to describe the q-axis, in which as $\alpha$ increases, the q-axis gets saturated and the $d$-axis cross-coupling exists. The latter is shown in Figure 5 as evidence.

The effect of asymmetric saturation is also noticed in Figure 5 which results in significant negative values of $L_{\mathrm{qf}}^{\text {ac }}$ larger than $L$ as $\alpha$ increases. In both machines, $L_{\mathrm{qf}}^{\text {ac }}$ is easily influenced by $I_{\mathrm{q}}$ before saturation. However, asymmetric saturation is sensitive in the DC-VRM. The latter is justified with reference to the field ratio $k_{\mathrm{f}}$ value of (23) shown in Figure 7. It is important to note that absolute values of $L_{\mathrm{qf}}^{\mathrm{ac}}$, classically assumed zero in (15), are even greater than $L_{\mathrm{dd}}^{\mathrm{ac}}$ and $L_{\mathrm{qq}}^{\mathrm{ac}}$ at some operating points of the DC-VRM e.g., at maximum torque current angle of Figure 5.

The effect of saturation-saliency is also noted in the decreasing saliency ratio $k_{\mathrm{s}}$ of (23) from Figure 7 for both machines. However, the WF-FSM is less affected by saturation-saliency effects compared to the DC-VRM.

The effect of cross-coupling and saturation-saliency introduces positive and negative $T_{\mathrm{m}}$ and $T_{\mathrm{r}}$, which largely reduces $T_{\mathrm{e}}$ from $T_{\mathrm{f}}$ at maximum torque current angle values, as shown in Figure 6 . As expected, these torque plot results suggest that cross-coupled saturation has more influence at high current conditions where the q-axis current is a maximum e.g., $T_{\mathrm{m}}$ is significant at maximum torque current angle in Figure 6. As $L=L_{\mathrm{qd}}=L_{\mathrm{dq}}$, (26) can also be expressed in terms of current magnitude and angle following Figure 1 as

$$
\begin{aligned}
T_{\mathrm{f}} & =1.5 Q I_{\mathrm{f}} I\left[L_{\mathrm{df}}^{\mathrm{ac}} \sin (\alpha)-L_{\mathrm{qf}}^{\mathrm{ac}} \cos (\alpha)\right] \\
T_{\mathrm{r}} & =0.75 Q\left(L_{\mathrm{dd}}^{\mathrm{ac}}-I_{\mathrm{qq}}\right) I^{2} \sin (2 \alpha) \quad,\left(L=L_{\mathrm{qd}}^{\mathrm{ac}}=L_{\mathrm{dq}}^{\mathrm{ac}}\right) . \\
T_{\mathrm{m}} & =-1.5 Q I^{2} L \cos (2 \alpha)
\end{aligned}
$$

The torques of (30) show that the reluctance and mutual torques are $90^{\circ}$ out of phase in variation of the current angle $\alpha$, a result confirmed in Figure 6. Thus, in Figure 6, the near maximum torque is shown to be at $90^{\circ}$, where the reluctance torque is zero and the cross-coupling mutual torque is at its negative maximum.

The power transferred to and from the machines during the current angle simulation range is represented by the power factor plots of Figure 8 calculated from (27). According to (29), at $\alpha=0^{\circ}$ and $180^{\circ}$ the power factor is zeros, as shown in Figure 8. The power factor increases with the current angle to a maximum value near $\alpha=45^{\circ}$ in both machines. Both machines achieve nearly the same power factor value at maximum torque current angle.

From the above described results of Figures $5-8$ it can be noticed that in both machines maximum torque and power factor are achieved when $k_{\mathrm{s}}$ is approximately a unit and $k_{\mathrm{f}}$ is near maximum, respectively. The latter essential parameter characteristics entirely depend on the influence of saturation. Hence, the proposed FPM procedure can be used not only in the design of the machines but also in the development of better controller strategies of the two variants of the WF-FMMs [21]. Consequently, useful hints for design and control of the WF-FMM are illuminated. The latter is also presented in Figure 9 where the conventional calculated inductances of (15) are shown compared to actual calculated inductances of (17), (19) and (21) in Figure 5. This is further demonstrated with the equivalent inductances shown in Figure 10. In Figure 10, the inductances $\left[L_{\mathrm{dd}}^{\mathrm{eq}}(11), L_{\mathrm{qq}}^{\mathrm{eq}}(11)\right]$ and $\left[L_{\mathrm{dd}}^{\mathrm{eq}}(12), L_{\mathrm{qq}}^{\mathrm{eq}}(12)\right]$ are calculated according to (11) and (12), respectively. Thus, it is evident from Figure 10 that the conventional calculated equivalent dq-axes inductances includes the effect of saturation. However, $L_{\mathrm{dd}}^{\mathrm{eq}}(11)$ do not match $L_{\mathrm{dd}}^{\mathrm{eq}}(12)$ because of the differences in the way the 
conventional ( $L_{\mathrm{df}}^{\mathrm{co}}$ of $(15)$ and actual $\left(L_{\mathrm{df}}^{\mathrm{ac}}\right.$ of $(17)$ in Figure 9) are calculated as explained in Section 2. As a result that the total q-axis will result in the equal total flux linkages after decomposition in both conventional numerical method and FPM, the equivalent inductances $L_{\mathrm{qq}(11)}^{\mathrm{eq}}$ and $L_{\mathrm{qq}(12)}^{\mathrm{eq}}$ are equal as shown in Figure 10.

A commercial FEM software package Ansys-Maxwell is utilized for validation of the described analysis in this paper. Figure 11 shows the WF-FMM models developed in Ansys-Maxwell. Figures 12 and 13 shows the steady-state total phase flux linkages and torque at rated current and near maximum torque current angle i.e., $\alpha=90^{\circ}$ versus the electrical rotor position angle $\theta_{\mathrm{e}}$ defined in Figure 1. The red continuous and blue dashed lines represent the flux linkages calculated from the proposed model (of (10) using (12)) and from Ansys-Maxwell, respectively. In Figure 13, $T_{\mathrm{i}}$, $T_{\mathrm{a}}$ are steady-state Maxwell stress tensor torques calculated using in-house, Ansys-Maxwell FEM software packages, respectively, and $T_{\mathrm{e}}$ is of (24). The results depict a good agreement which proves the validation of the analysis presented in this paper. Note has to be taken that although Ansys-Maxwell is used for validation purposes, the transient simulation is time consuming when compared to the proposed static FEM-based analysis. The latter makes it suitable the proposed analysis in design optimization.
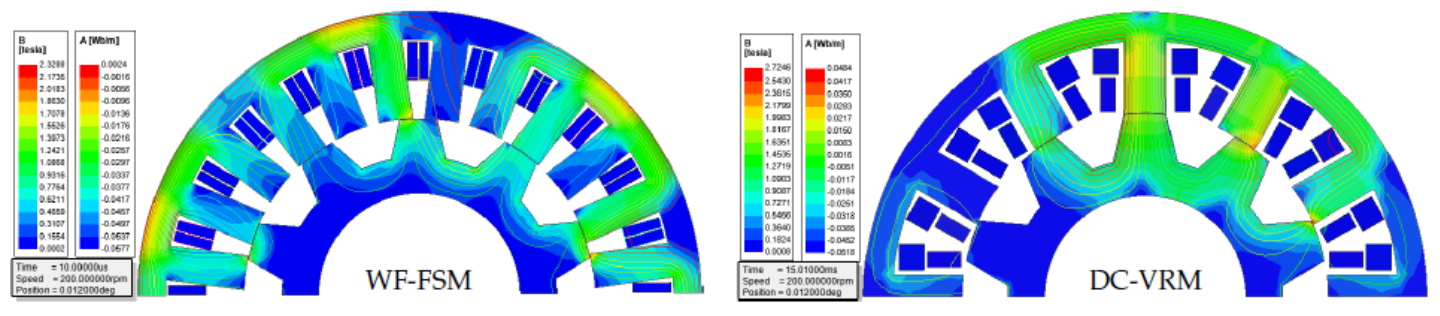

Figure 11. Three-phase WF-FMM models in transient 2D-Ansys-Maxwell showing flux density and lines distribution at rated currents (phase and field) and given rotor position. Phase/DC slots (left) 24/24 WF-FSM and (right) 12/24 DC-VRM.
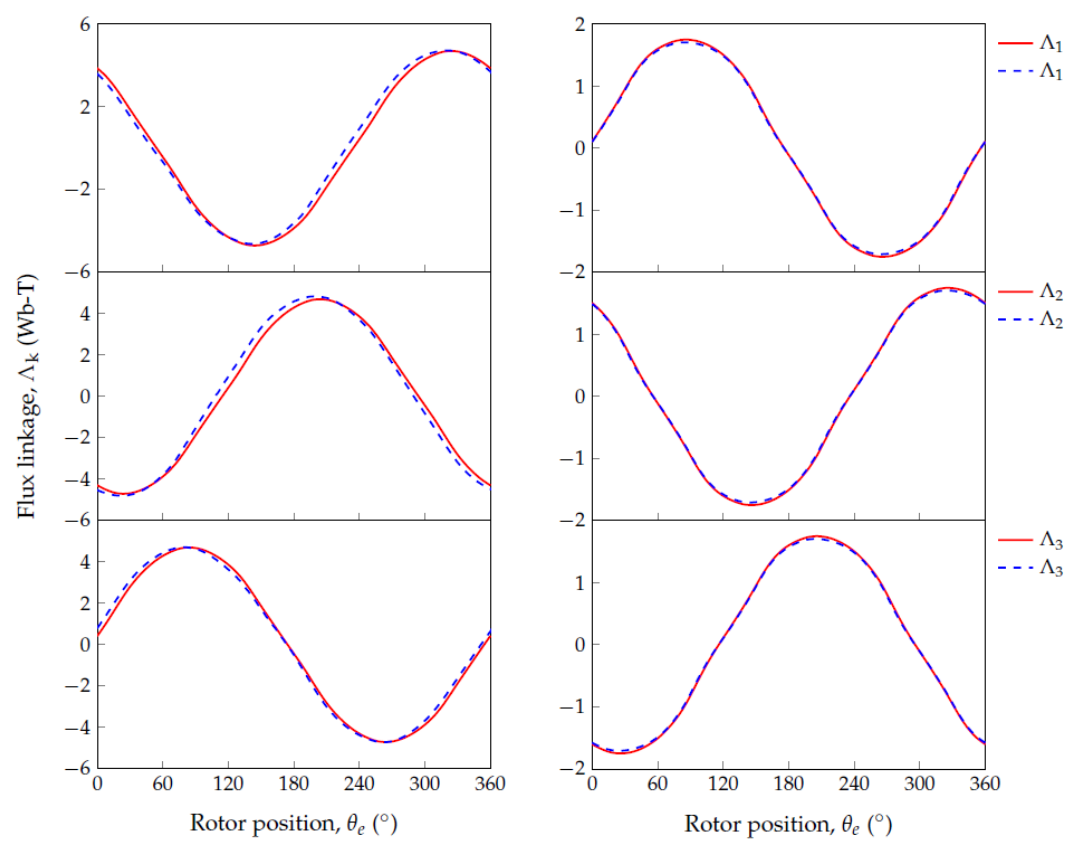

Figure 12. WF-FMM phase flux linkages of (left) WF-FSM and (right) DC-VRM versus rotor positions at rated currents (phase and field) and an operating current angle $\alpha=90^{\circ}$. Proposed model—continuous line and Ansys-Maxwell—dashed line. 

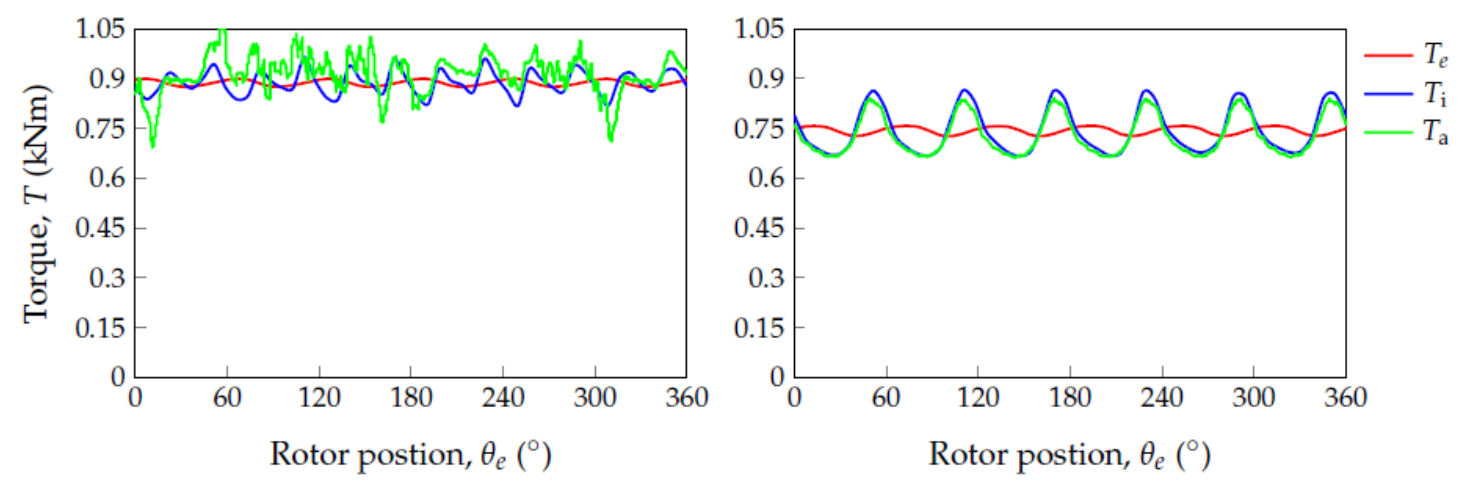

Figure 13. WF-FMM torque of (left) WF-FSM and (right) DC-VRM versus rotor positions at rated currents (phase and field) and an operating current angle $\alpha=90^{\circ}$. Proposed model-continuous line and Ansys-Maxwell—dashed line.

\section{Conclusions}

The use of an FEM-based non-classical modeling approach for WF-FS and DC-VR machines on a $15 \mathrm{~kW}$ power level has been illustrated in this paper. The approach illuminates the severe saturation effects (saturation-saliency and cross-coupling) on the model parameters of the machines at different operating points, leading to better analysis and understanding. Using electromagnetic static finite element solutions, the approach ensures accurate and computational efficient performance calculation of the two variants of WF-FMMs. In the following, the main conclusions drawn from the work in this paper are stated:

Accuracy is guaranteed on the calculation of the WF-FM machine parameters for performance, only if cross-magnetization and asymmetric saturation are considered. This is found to be critical when the q-axis current is high at maximum torque.

A less saturated WF-FSM could be more affected by cross-magnetization effect compared to the the less saturated DC-VRM, due to overlapping and less spacing between the phase- and field-winding of the former.

It is interesting that the field windings of WF-FM machines, which are aligned with the d-axes, also generates a cross-coupling q-axis field caused by relatively huge asymmetric distribution of the saturated finite element permeabilities in the machine. The q-axis field inductance $L_{\mathrm{qf}}^{\mathrm{ac}}$ is calculated to be as high as $20 \%$ and $63 \%$ of the d-axis field inductance $L_{\mathrm{df}}^{\text {ac }}$ for the WF-FSM and DC-VRM respectively. In the case of the DC-VRM, $L_{\mathrm{qf}}^{\mathrm{ac}}$ is even absolutely larger than the self inductances $L_{\mathrm{dd}}^{\mathrm{ac}}$ and $L_{\mathrm{qq}}^{\mathrm{ac}}$ under deep saturation, i.e., $\alpha=90^{\circ}$. This leads to a large error in the equivalent q-axis inductance, $L_{\text {qeq, }}^{\text {ac }}$, if not taken into account.

The torques of both WF-FM machines as shown can be effectively segregated into components using the accurately calculated machine parameters. The contribution of each torque component can be used a better analyses tool in the synthesis and design optimization of both machines. It is shown, for example, that the reduced coupling or mutual torque is relatively large in both machines at maximum torque current angle. Thus, although the cross-coupling inductances are shown to be small in both machines, these inductances must not be ignored in both equivalent inductances and are essential in the torque calculation.

From the evaluated saliency $\left(k_{\mathrm{s}}\right)$ and field $\left(k_{\mathrm{f}}\right)$ ratios, it is clear that maximum torque and power factor of both WF-FM machines occur when $\alpha$ is slightly more than $90^{\circ}$ and slightly below $45^{\circ}$, respectively. This is clearly an indication of trade-off in their drive performance desirabilities.

Author Contributions: Conceptualization, U.B.A. and M.J.K.; methodology, M.M. and U.B.A.; software, M.M.; validation, M.M. and U.B.A.; formal analysis, M.M., U.B.A. and M.J.K.; investigation, M.M.; resources, M.J.K.; data curation, M.M.; writing—original draft preparation, U.B.A. and M.M.; writing-review and editing, M.M., U.B.A. and M.J.K.; visualization, M.M.; supervision, U.B.A. and M.J.K.; project administration, M.M.; funding acquisition, M.J.K. and U.B.A. All authors have read and agreed to the published version of the manuscript. 
Funding: This research is partly funded by Stellenbosch University, South Africa and the APC is funded by Stellenbosch University, South Africa, and Tshwane University of Technology, South Africa.

Conflicts of Interest: The authors declare no conflict of interest.

\section{References}

1. Jahns, T. Getting Rare-Earth Magnets Out of EV Traction Machines: A review of the many approaches being pursued to minimize or eliminate rare-earth magnets from future EV drivetrains. IEEE Electrif. Mag. 2017, 5, 6-18. [CrossRef]

2. Li, D.; Qu, R.; Li, J. Topologies and analysis of flux-modulation machines. In Proceedings of the 2015 IEEE Energy Conversion Congress and Exposition (ECCE), Montreal, QC, Canada, 20-24 September 2015; pp. 2153-2160. [CrossRef]

3. Jia, S.; Qu, R.; Li, J.; Li, D. Principles of Stator DC Winding Excited Vernier Reluctance Machines. IEEE Trans. Energy Convers. 2016, 31, 935-946. [CrossRef]

4. Mabhula, M.; Akuru, U.B.; Kamper, M.J. Numerical Estimation of Cross-Coupling Inductance Effects on the Performance of Wound-Field Flux Modulation Machines. In Proceedings of the Intermag Americas, Montréal, QC, Canada, 4-8 May 2020; p. 405.

5. Zhu, X.; Lee, C.H.T.; Chan, C.C.; Xu, L.; Zhao, W. Overview of Flux-Modulation Machines Based on Flux-Modulation Principle: Topology, Theory, and Development Prospects. IEEE Trans. Transp. Electrif. 2020, 6, 612-624. [CrossRef]

6. Khan, F.; Sulaiman, E.; Ahmad, M.Z. Review of Switched Flux Wound-Field Machines Technology. IETE Tech. Rev. 2017, 34, 343-352. [CrossRef]

7. Lin, M.; Qu, R.; Li, J.; Jia, S.; Lu, Y. Torque ripple reduction techniques for stator DC winding excited vernier reluctance machines. In Proceedings of the 2016 IEEE Energy Conversion Congress and Exposition (ECCE), Milwaukee, IL, USA, 18-22 September 2016; pp. 1-8.

8. Pang, J.; Liu, W.; Jiao, N.; Wang, J.; Ma, P. Calculation of Cross-Coupling Inductance and Electromagnetic Torque in Wound-Rotor Synchronous Starter/Generator. IEEE Trans. Ind. Electron. 2019, 66, 5115-5123. [CrossRef]

9. Hua, W.; Ming, C. Inductance characteristics of 3-phase flux-switching permanent magnet machine with doubly-salient structure. In Proceedings of the 2006 CES/IEEE 5th International Power Electronics and Motion Control Conference, Shanghai, China, 14-16 August 2006; pp. 1-5. [CrossRef]

10. Ilhan, E.; Kremers, M.F.J.; Motoasca, E.T.; Paulides, J.J.H.; Lomonova, E.A. Sensitivity analysis for phase inductances in Flux-Switching PM machines. In Proceedings of the 2012 XXth International Conference on Electrical Machines, Marseille, France, 5 September 2012; pp. 763-768. [CrossRef]

11. Bao, J.; Gysen, B.L.J.; Boynov, K.; Paulides, J.J.H.; Lomonova, E.A. Torque Ripple Reduction for 12-Stator/10-Rotor-Pole Variable Flux Reluctance Machines by Rotor Skewing or Rotor Teeth Non-Uniformity. IEEE Trans. Magn. 2017, 53, 1-5. [CrossRef]

12. Li, G.; Zhu, Z.; Jewell, G. Performance investigation of hybrid excited switched flux permanent magnet machines using frozen permeability method. IET Electr. Power Appl. 2015, 9, 586-594. [CrossRef]

13. Mabhula, M.; Kamper, M.J. Saliency and mutual inductance effect in cylindrical wound-rotor synchronous motor. In Proceedings of the 2017 IEEE Workshop on Electrical Machines Design, Control and Diagnosis (WEMDCD), Nottingham, UK, 20-21 April 2017; pp. 152-157. [CrossRef]

14. Rockhill, A.A.; Lipo, T.A. A generalized transformation methodology for polyphase electric machines and networks. In Proceedings of the 2015 IEEE International Electric Machines Drives Conference (IEMDC), Coeur d'Alene, ID, USA, 10-13 May 2015; pp. 27-34.

15. Umans, S.; Fitzgerald, A.; Kingsley, C. Electric Machinery, 7th ed.; McGraw-Hill Higher Education: New York, NY, USA, 2013.

16. Ide, K.; Wakui, S.; Shima, K.; Takahashi, M.; Miyakawa, K.; Yagi, Y. Analysis of saturated synchronous reactances of large turbine generator by considering cross-magnetizing reactances using finite elements. IEEE Trans. Energy Convers. 1999, 14, 66-71. [CrossRef]

17. Kim, M.; Sul, S.; Lee, J. Compensation of Current Measurement Error for Current-Controlled PMSM Drives. IEEE Trans. Ind. Appl. 2014, 50, 3365-3373. [CrossRef] 
18. Zhu, Z.Q.; Li, Y.; Howe, D.; Bingham, C.M.; Stone, D. Influence of Machine Topology and Cross-Coupling Magnetic Saturation on Rotor Position Estimation Accuracy in Extended Back-EMF Based Sensorless PM Brushless AC Drives. In Proceedings of the 2007 IEEE Industry Applications Annual Meeting, New Orleans, LA, USA, 23-27 September 2007; pp. 2378-2385.

19. Walker, J.A.; Dorrell, D. Verification of the frozen permeabilities method of calculating the interior permanent magnet motor. In Proceedings of the 2005 IEEE International Magnetics Conference (INTERMAG), Nagoya, Japan, 4-8 April 2005; pp. 715-716.

20. Gerber, S. SEMFEM User's Manual; Stellenbosch University: Stellenbosch, South Africa, 2014.

21. Herold, T.; Franck, D.; Lange, E.; Hameyer, K. Extension of a d-q model of a permanent magnet excited synchronous machine by including saturation, cross-coupling and slotting effects. In Proceedings of the 2011 IEEE International Electric Machines Drives Conference (IEMDC), Niagara Falls, ON, Canada, 15-18 May 2011; pp. 1363-1367.

Publisher's Note: MDPI stays neutral with regard to jurisdictional claims in published maps and institutional affiliations.

(C) 2020 by the authors. Licensee MDPI, Basel, Switzerland. This article is an open access article distributed under the terms and conditions of the Creative Commons Attribution (CC BY) license (http://creativecommons.org/licenses/by/4.0/). 